\title{
Three-Dimensional Progressive Damage Analysis of Composite Laminates Containing a Central hole Subjected to Compressive Loading
}

\author{
Danyong Wang \\ Institute 53 of China North Group Corporation \\ Jinan, China, +86 053185878073 \\ wangdanyong@vip.sina.com
}

\author{
Weidong Wen \\ College of Energy \& Power Engineering, Nanjing University \\ of Aeronautics and Astronautics \\ Nanjing, China
}

\begin{abstract}
A numerical method is developed for the application of three-dimensional progressive damage analyses in composite laminates containing an open hole with arbitrary geometry and stacking sequence subjected to static compressive loading. The method developed is included in the three-dimensional FEM stress analysis, failure analysis based on three-dimensional Hashin type criterion, the material property degradation rule of ply discount. It is capable of numerically simulating the whole process of failure initiation, propagation and catastrophic failure of the structure and of predicting the ultimate strengths and failure modes of composite laminates containing an open hole. Two different lay orientations and four different $W / D$ with an open hole are analyzed for the ultimate strength and damage progression. On the other hand, four damage mechanisms and the correlation among the damage are studied and discussed in this paper. An excellent agreement was found between data obtained from this study and the existing literature.
\end{abstract}

Keywords-Laminates; Damage mechanics; Delamination; Strength; Finite element analysis(FEA)

\section{INTRODUCTION}

Composite materials have been extensively used in engineering and become an important material in aeronautic and astronautic structures. Due to the needs of connecting and other designing, all kinds of holes or cutouts must exist in composite structures, which induce stress concentrations around holes or cutouts, make damage accumulation complicated and decrease the strength of composite structures. If the composite structures are designed to be used in load bearing applications, the primary consideration is the evaluation of their load carrying capacity in compression. one proper method should be applied to analyze stress and failure of composite laminates containing holes or cutouts subjected to compression.

Composite laminates containing holes or cutouts have been an important concern in some literatures ${ }^{[1-19]}$. Some researchers ${ }^{[1-3]}$ applied two-parameter methods that are based on Whitney-Nuismer ${ }^{[21-23]}$ failure criterion for unloaded holes and two parameters considered that are the unnotched tensile strength and a characteristic dimension. Two approaches that are the point stress and the average stress methods were proposed for predicting the strength of unloaded holes in tension and of both unloaded and loaded holes in compression. The characteristic distance will change when the layer orientation alters in the laminates, inducing difficultly to determinate the characteristic distance for laminates with all kinds of layer orientation. More fracture-mechanics models are proposed and 'kink band' propagation in composite laminates with a open hole was studied by experimental investigation in Refs. ${ }^{[4-8]}$, which were semi-empirical and required information on some empirical parameters introduced along with the analyses. Soutis ${ }^{[9-13]}$ developed a linear softening cohesive zone model to predict the effects of hole size and lay-up upon the compressive strength and microbuckle zone size at failure. Some experimental techniques ${ }^{[14-16]}$ were developed to studied failure characteristics and compressive failure initiation and progression mechanisms of composite laminates in compression. Nevertheless, analyses mentioned above only provided little information on the extent of damage and the types of damage in the laminates during loading.

With manufacture techniques of composite materials improving increasingly and the material mechanics characteristics such as strength, stiffness and so on better and better gradually, the basic damage mechanisms of the degradation of material property need to be analyzed for composite structures subjected to all kinds of loadings in order to utilize adequately the potential of composites, which proposes to be an effective approach for designing composite structures.

Chang et al. ${ }^{[17-19]}$ developed a two-dimensional progressive damage model considering three different failure modes to predict damage accumulation and the strength of composite laminates containing unloaded holes and loaded holes by integrating failure criteria of Yamada-Sun ${ }^{[23]}$ and Hashin ${ }^{[24]}$. But only in-plane ply failure was evaluated in such model, out-of-plane failure such as delamination was not considered in these analyses and the model needed the ply orientation of the laminates which must be symmetric with respect to the middle plane of the plate.

There are some disadvantages for applying the two-dimensional finite element method that can't analyze stress distributions around holes, layer orientations and delamination accurately, which can be solved by using the three-dimensional finite element method. But lots of 
three-dimensional progressive damage researches ${ }^{[25-31]}$ have been studied on the composite laminates containing loaded holes or unloaded holes only subjected to tensile loading. Unfortunately, there are no three-dimensional models available which can analyze all types of damage mechanisms for laminated composites containing holes or cutouts subjected to compressive loadings. To consider four basic failure modes of damage simultaneously, the correlation among them in notched composites due to compression is still not well understood.

Therefore, the objective of this investigation is to develop a numerical method to predict the strength, the types and size of damage inside the laminates containing a hole subjected to compressive loadings. Finally, two different lay orientations and four different $W / D$ of composite laminates containing a central hole from the literature ${ }^{[19]}$ is adopted to predict their damage accumulation and their compressive strengths, the results of which are compared with experimental results of the strength from the literature.

\section{ANALYSIS METHOD}

In this section, the theoretical basis of the three-dimensional progressive damage approach is briefly introduced. Geometry of the laminate containing a central hole is illustrated in Figure 1.

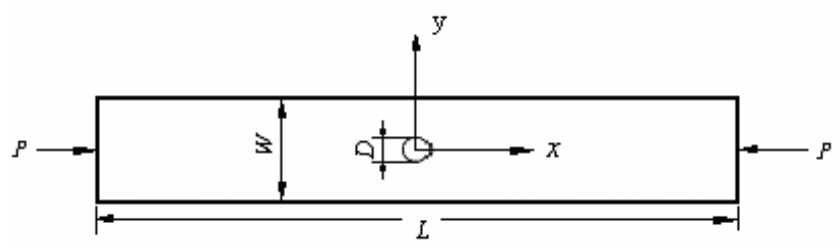

Figure 1. Illustration of the basic geometry of the laminate containing a central hole

$W$ is the width of the laminate. $D$ is the diameter of the central hole. $P$ is the force of compressive loading. $L$ is the length of the laminate. The ply orientation of the laminate can be arbitrary.

\section{A. Stress Analysis}

A three-dimensional stress analysis was applied to composite laminates containing holes, which could exactly analyze stress distribution, layer sequence and delamination and so on.

\section{B. Failure Analysis}

Failure mechanisms of composite structures are very complex. Proper failure criteria need be used to detect damage for diverse damage modes. The three-dimensional Hashin-type criterion $^{[24]}$ has been developed successfully and applied to analyze damage failures by many researchers ${ }^{[26-31]}$, which is also applied in this paper.

The laminates will loss the ability of supporting loadings when the damage accumulation reaches to a critical point, which will make the structure catastrophic. This model proposes that the laminate containing a central hole will reach final failure when the damage of all plies expands to the boundary of the laminates.

\section{Material Property Degradation Rules}

The material properties will be degraded in the damage areas once damage occurs in the laminate. Many researchers [17-19,26-34] proposed diverse material property degradation rules according to the capability of composite materials studied, which are based on experimental results. In the paper, damage detected is simulated by degrading the material properties of the failed elements. An appropriate property degradation rule has to be introduced to describe the physics of the damage mechanisms. The ply discount approach is used to consider the laminate property degradation rule. The property degradation rule is used same as the literature [35] in this paper.

In fact, the four basic damage mechanisms which are matrix cracking, fiber fracture, fiber-matrix shearing and delamination have interactive correlations. Two or more failure types of damage may occur in the same damage area. A type of damage mode occurred firstly can subsequently induce other modes of damage to occur with the compressive loading increasing. The material property degradation of failed elements including several failure modes of damage may be dealt with superpose. Each material property degradation rule of damage types occurred in the failed elements.

\section{THE THREE-DIMENSIONAL FINITE}

ELEMENT MODEL AND THE ANALYSIS FLOW

A parametric three-dimensional progressive damage model based on ANSYS which is a business soft was created. The model adopted three-dimensional eight-node SOLID46 layered element which has three displacement degrees of freedom at each node of composite laminates. The thickness of the lamina is adopted as the thickness of the element is advantage to analyze shear stresses between layers. Some important geometric parameters such as the diameter of the laminate, the number of layer, the thickness of the lamina, layer angles and the length of the laminate are chosen. The model may automatically build up the laminate containing a central hole with arbitrary sizes, layer sequences and material properties, improving the efficiency of analysis. Meshes around the hole are dense for analyzing stress distributions accurately.

The flowchart of analysis is explained, narrated briefly as follows:

First, geometry, material constants, boundary conditions, initial loads, the incremental load and so on are defined and then we create a three-dimensional finite element model.

Second, analyze the stress, calculate and average on-axis stresses for each element of the laminate at Gauss points.

Third, check out whether damage has occurred in the elements of the laminate containing a central hole. If damage hasn't been checked out in all elements, the load will be incremented and the analysis of stresses will be executed in the next step. If damage occurs and the catastrophe hasn't happened, the material is degraded in the damaged elements according to the material property degradation rules mentioned above and the stress analysis is renewed to calculate in the step and the recalculated process will stop until no damage is checked out in the load step. The load is incremented, the cycle 
returns to the second step. If the catastrophe happened, the program should stop.

\section{RESULTS AND DISCUSSION}

In order to verify the accuracy of the three-dimensional progressive damage model, the predictions generated by the model are compared to the available experimental data in the literature[19]. The material properties of T300/976 composite used in the calculations refer the literature [19]. Two different ply orientations and four different $W / D$ laminates containing a central hole are selected for the comparisons. The nonlinear solve is used. Analysis of stresses, failure check and material property degradation are progressed in each loading process until making sure that the laminate containing a central hole is a catastrophe. A finite element mesh for the laminate containing a central hole calculated is present in Figure 2. The initial applied load is $10 \mathrm{MPa}$, which is small enough that any damages don't occurr in the laminates. The incremental load $\Delta P$ is also $10 \mathrm{MPa}$. To illustrate the damage progression and the extent of damage in the laminates containing a central hole

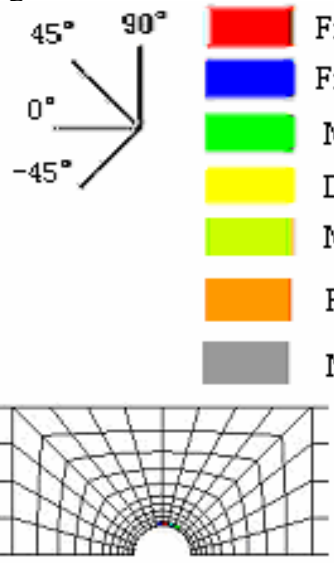

$230 \mathrm{MPa}$
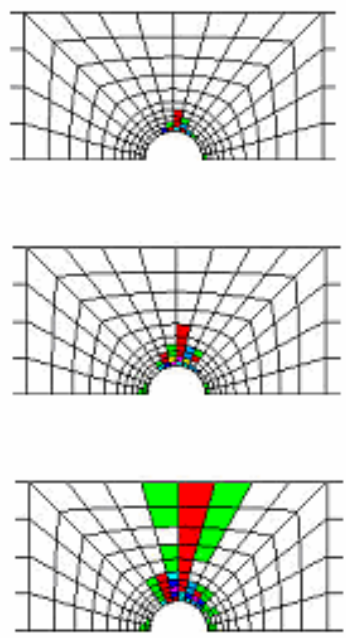

$0^{\circ}$ layer

the first layer

\section{Fiber breakage}

Fiber-matrix shearing

Matrix cracking

Delamination

Matrix cracking - delamination

Fiber-matrix shearing - matrix cracking - delamination

Matrix cracking - delamination - fiber-matrix shearing during compressive loading, results of computer simulations are obtained by the present model for selected laminates.

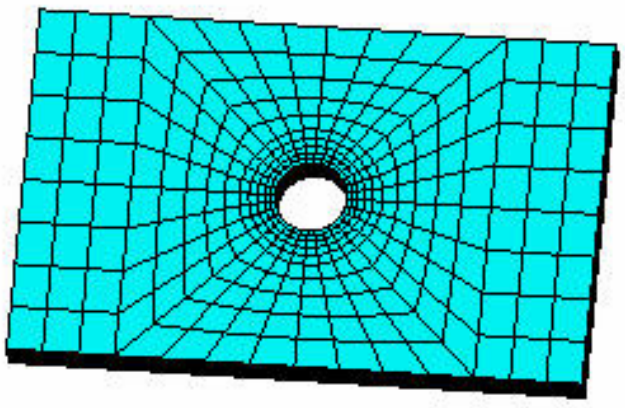

Figure 2.The finite element model of the composite laminate containing a central hole

\section{A. Damage Accumulation of $\left[(0 / \pm 45 / 90)_{3}\right]_{s}$ Laminates} Containing a Hole

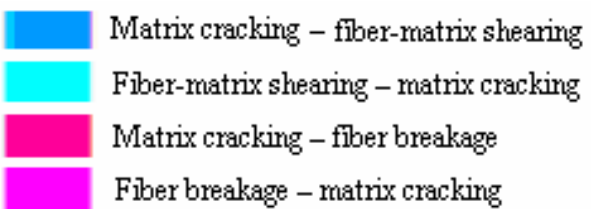

Fiber breakage - matrix cracking

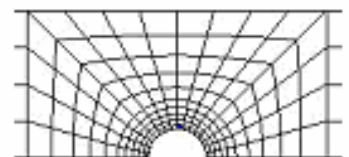

$220 \mathrm{MPa}$

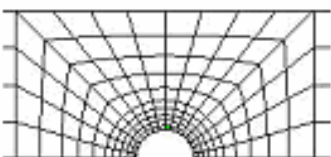

$220 \mathrm{MPa}$
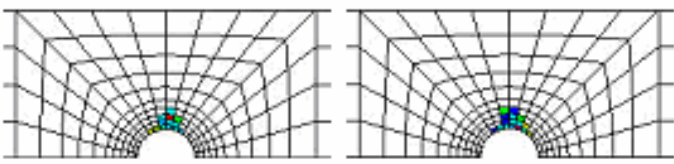

$300 \mathrm{MPa}$

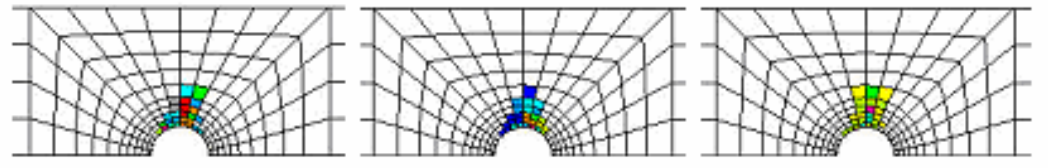

$340 \mathrm{MPa}$

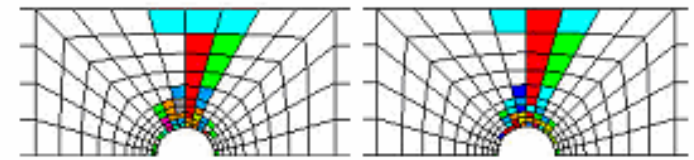

$$
45^{\circ} \text { layer }
$$

$360 \mathrm{MPa}$

the second layer
$230 \mathrm{MPa}$
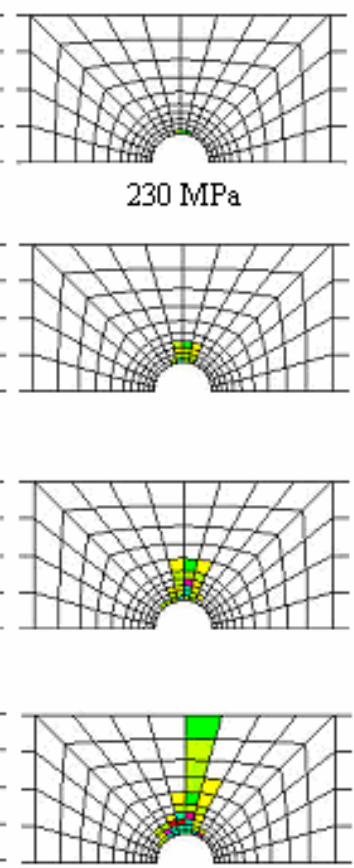

$90^{\circ}$ layer

the fourth layer

Figure 3. Illustration of damage propagation predicted by the present model at different load levels for $\left[(0 / \pm 45 / 90)_{3}\right]_{\mathrm{S}}$ laminate containing a central hole. $D=$ $0.0635 \mathrm{~m}, W / D=5$ 
Figure 3 demonstrates the predicted damage progression in a $\left[(0 / \pm 45 / 90)_{3}\right]_{S}$ laminate containing a central hole at different load levels. Damage initiates from the hole boundary, near the stress concentrations. In $0^{\circ}$ layers, fiber-matrix shearing, fiber breakage and matrix cracking initiate near the stress concentrations at the load of $230 \mathrm{MPa}$. In $90^{\circ}$ layers, matrix cracking and matrix cracking - delamination initiates near the stress concentrations at the load of $230 \mathrm{MPa}$, whereas fiber-matrix shearing and matrix cracking initiate near the stress concentrations in $\pm 45^{\circ}$ layers at the load of $220 \mathrm{MPa}$.

Comparing with the extending direction of $\left[(0 / 90)_{6}\right]_{\mathrm{S}}$ laminates, the laminates of $[0 / \pm 45 / 90]_{S}$ don't extend along the direction of loading. Damage always grows in the direction normal to the loading direction.

Finally, as the load approaches the final load of $360 \mathrm{MPa}$, the damage propagates very rapidly along the direction normal to loading direction to the free edges of the laminate, causing to the total failure of the laminate containing a central hole. The ultimate load of $360 \mathrm{MPa}$ is predicted.

For $0^{\circ}$ layers, the failure modes are mainly dominated by fiber breakage and matrix cracking, but there are some correlative failure modes which are fiber-matrix shearing matrix cracking and matrix cracking - fiber-matrix shearing. For $\pm 45^{\circ}$ layers, the failure modes are mainly dominated by fiber breakage, fiber-matrix shearing - matrix cracking and matrix cracking - fiber-matrix shearing, but there are more correlative failure modes than that of $0^{\circ}$ layers. By examining the failure modes, it is interesting to find that two correlative failure modes that are fiber-matrix shearing - matrix cracking delamination and matrix cracking - delamination fiber-matrix shearing respectively occur in the damage areas. Even if the basic failure modes of damage in the two correlative failure modes are same, the sequence of damage occurred isn't same, which accounts for the very complex damage mechanisms. A few failure modes of delamination and matrix cracking - delamination also exist around the stress concentrations in $\pm 45^{\circ}$ layers. For $90^{\circ}$ layers, other than damage of $0^{\circ}$ layers and $\pm 45^{\circ}$ layers, the failure modes are mainly dominated by matrix cracking - delamination and delamination. A few failure modes of matrix cracking delamination - fiber breakage, fiber breakage, matrix cracking and fiber breakage - matrix cracking also exist in the damage areas.

Comparisons on the compressive strengths between the predictions and the experimental data of the composites containing a central hole of four different width-to-diameter ratios $(W / D)$ are presented in Figure 4. Overall, the predictions agree with the test data very well. The result indicates that the bearing strength increases with the increase of the laminate width and quasi-isotropic laminates exhibits lower compressive strengths than cross-ply laminates.

\section{B. Compressive strength of $\left[(0 / 90)_{6}\right]_{s}$ Laminates Containing a Hole}

The effect of $\left[(0 / 90)_{6}\right]_{\mathrm{S}}$ laminates containing a central hole at various width-to-diameter ratios on the compressive strength is shown in Figure 5. In the figure, the measured strengths of cross-ply laminates with four different width-to-diameter ratios in the literature[19] are compared with predictions of the model. The result indicates that the compressive strength increases with the increase of the laminate width-to-diameter ratio and the calculated failure strengths agree with the data within $15 \%$ for four cases considered.

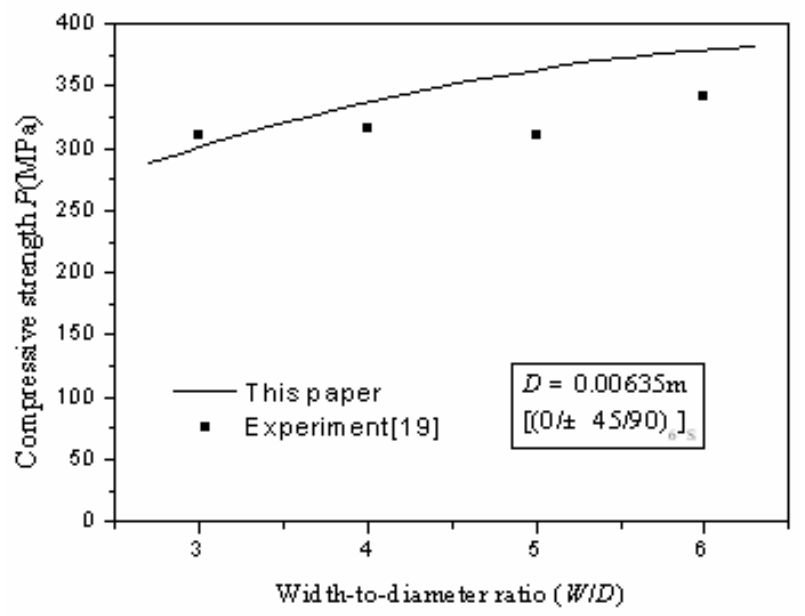

Figure 4. Comparisons between the experimental data and the results of the present model for compressive strengths of $\left[(0 / \pm 45 / 90)_{3}\right]_{\mathrm{S}}$ laminates containing a hole at various width-to-diameter ratios

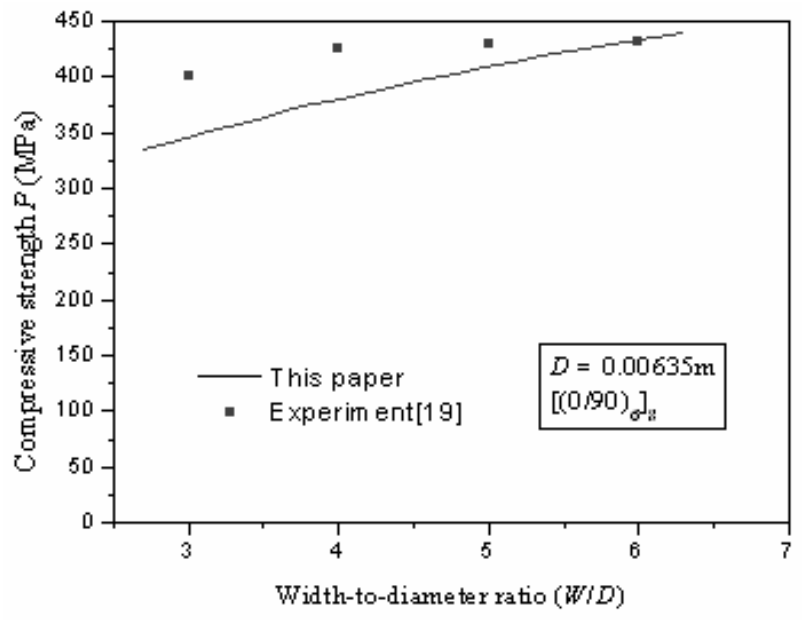

Figure 5. Comparisons between the experimental data and the results of the present model for compressive strengths of $\left[(0 / 90)_{6}\right]_{\text {S laminates containing a }}$ hole at various width-to-diameter ratios

\section{V.CONCLUSIONS}

The detailed numerical investigation on the structural behavior of laminated composites containing a central hole subjected to compressive loadings has been presented. Based on the numerical results, the conclusions can been drawn as follows:

(1) The three-dimensional progressive model can simulate the damage accumulation accurately in the laminates and predict the ultimate strengths and failure modes of composite laminates containing a hole subjected to compressive loadings successfully. 
(2) Comparisons with different analyses have been performed to show that damage in laminates containing a hole is always confined to the areas near the stress concentrations at the initial loading stages, then damage grows from the stress concentration areas as the applied load continues to increase till the load approaches to the final failure load.

(3) The results of the damage propagation predicted by the model show that the majority of the damage in compression loaded for open hole composite laminates is matrix delamination, delamination and fiber breakage. It is very visible that the four basic failure modes of damage are correlative. One failure mode of damage occurred firstly may induce to other failure modes of damage in the same area subsequently.

\section{Acknowledgment}

The authors would like to acknowledge financial support from Institute 606.

\section{REFERENCES}

[1] M. D. Rhodes, M. M. Mikulas, P. E. McGowan. "Effects of orthotropy and width on the compression strength of graphite-epoxy panels with holes", AIAA Journal, 1987, 22(9), pp. 1283-1292.

[2] S. C. Tan. "Tensile and compressive notched strength of PEEK matrix composite laminates", Journal of Composite Materials, 1987, 6, pp. 253-267.

[3] P. H. Chen, Z. Shen, J. Y. Wang. "Prediction of the strength of notched fiber-dominated composite laminates", Composites Science and Technology, 2001, 61(9), pp. 1311-1321.

[4] E. G. Guynn, W. L. Bradley. "Measurements of the stress supported by the crush zone in open composite laminates loaded in compression", Journal of Reinforced Plastics and Composites, 1989, 8(2), pp. 133-149.

[5] E. G. Guynn, W. L. Bradley, W. Elber. "Micromechanics of compression failure in open hole composite laminates", Compoiste Materials: Fatigue and Fracture, Second Volume, ASTM STP 1012, ASTM, 1989, pp. $118-136$.

[6] E. G. Guynn, W. L. Bradley. "A detailed investigation of the micromechanisms of compressive failure in open hole composite laminates", Journal of composite materal, 1989, 23, pp. 479-504.

[7] M. W. Anthony, J. Ahn, R. K. Amir. "Compressive failure of notched uniply composite laminates", Composite Part B: Engineering, 1998, 29(1), pp.75-80.

[8] M. G. Toribio, S. M. Spearing. "Compressive response of notched glass-fiber epoxy/honeycomb sandwich panels", Composites Part A: Applied Science and Manufacturing, 2001, 32(6), pp. 859-870.

[9] C. Soutis, N. A. Fleck. "Static compression failure of carbon fibre T800/924C composite plate with a single hole", Journal of Composite materials, 1990, 24(5), pp.536-558.

[10] C. Soutis, N. A. Fleck, P. A. Smith. "Failure prediction technique for compression loaded carbon fibre-epoxy laminated with open holes", Journal of Composite Materials, 1991, 25(11) , pp.1476-1498.

[11] C. Soutis, F. C. Smith, F. L. Matthews. "Predicting the compressive engineering performance of carbon fibre-reinforced plastics", Composites Part A: Applied Science and Manufacturing, 2000, 31(6) , pp. 531-536.

[12] C. Soutis, P. T. Curtis, N. A. Fleck. "Compressive failure of notched carbon fibre composites", Proceeding of the Royal Society of London, Series A, 1993, 440, pp. 241-256.

[13] C. Soutis, E. C. Edge. "A method of the production of carpet plots for notched compression strength of carbon fibre reinforced plastic multidirectional laminates", Proceedings of the I MECH E Part G Journal of Aerospace Engineering, 1997, 211, pp. 251-261.

[14] M. F. Pinnell. "An examination of the effect of composite constituent properties on the notched-strength performance of composite materials",
Composites Science and Technology, 1996, 56(12), pp. 1405-1413.

[15] J. Wang, P. J. Callus, C. Bannister. "Experimental and numerical investigation of the tension and compression strength of un-notched and notched quasi-isotropic laminates", Composite Structures, 2004, 64(3-4), pp. 297-306.

[16] M. Saha, R. Prabhakaran, W. A. Waters. "Compressive behavior of pultruded composite plates with circular holes", Composite Structures, 2004, 65(1), pp. 29-36.

[17] F. K. Chang, L. B. Lessard, J. M. Tang. "Compression response of laminated composites containing an open hole laminates", SAMPE Quarterly, 1988, 19(4), pp. 46-51.

[18] F. K. Chang, L. B. Lessard. "Damage tolerance of laminated composites containing an open hole and subjected to compressive loadings: part I analysis", Journal of Composite Materials, 1991, 25, pp. 2-43.

[19] L. B. Lessard, F. K. Chang. "Damage tolerance of laminated composites containing an open hole and subjected to compressive loadings: part II experiment", Journal of Composite Materials, 1991, 25, pp. 44-64.

[20] J. M. Whitney, R. J. Nuismer. "Stress fracture criteria for laminated composites containing stress concentration", Journal of Composite Materials, 1974, 10, pp. 253-265.

[21] R. J. Nuismer, J. D. Labor. "Application of the average stress failure criteria : part I - tension”, Journal of Composite Materials, 1979, 12, pp. 238-249.

[22] R. J. Nuismer, J. D. Labor. "Application of the average stress failure criteria : part II - compression”, Journal of Composite Materials, 1979, 13, pp. 49-60

[23] S. E. Yamada, C. T. Sun. "Analysis of laminate strength and its distribution", Journal of Composite Materials, 1978, 12, pp. 275-284.

[24] Z. Hashin. "Failure criteria for unidirectional fiber composites", Journal of Applied Mechanics, 1980, 47, pp. 329-334.

[25] B. N. Nguyen. "Three-dimensional modeling of damage in laminated composites containing a central hole", Journal of Composite Materials, 1997, 31, pp. 1672-1693.

[26] W. H. Chen, S. S. Lee, J. T. Yeh. "Three-dimensional contact stress analysis of a composite laminate with bolted joint", Composite Structures, 1995, 30, pp. 287-297.

[27] P. P. Camanho, F. L. Matthews. "A progressive damage model for mechanically fastened joints in composite laminates", Journal of Composite Materials, 1999, 23, pp. 2248-2249.

[28] T. Kermanidis, G. Labeas, K. I. Tserpes, S. Pantelakis. "Finite element modeling of damage accumulation in bolted composite joints under incremental tensile loading", Internet: European Congress on Computational Method in Applied Sciences and Engineering ECCOMAS 2000, Barcelona, 11-14 September 2000.

[29] K. I. Tserpes, G. Labeas, P. Papanikos, T. Kermanidis. "Stength prediction of bolted joints in graphite/epoxy composite laminates", Composites: Part B, 2002, 33, pp. 521 529.

[30] A. Riccio, F. Scaramuzzino. "Influence of damage onset and propagation on the tensile structural behavior of protruding composite joints", 4th GRACM Congress on Computation Mechanics GRACM, 2002, Patras, 27-29, 2002.

[31] M. M. Shokrieh, L. H. Lessard. "Effects of material nonlinearity on the three-dimensional stress state of pin-loaded composite laminates", Journal of Composite Materials, 1996, 30(7), pp. 839-861.

[32] F. K. Chang, K. Y. Chang. "Post-failure analysis of bolted composite joints in tension or shear-out mode failure", Journal of Composite Materials, 1987, 21, pp. 809-833.

[33] K. Y. Chang, S. Liu, F. K. Chang. "Damage tolerance of laminated composites containing an open hole and subjected to tensile loadings", Journal of Composite Materials, 1991, 25, pp. 274-301.

[34] F. K. Chang, K. Y. Chang. "A progressive damage model for laminated composites containing stress concentrations", Journal of Composite Materials, 1987, 21, pp. 834-855.

[35] D. Y. Wang, W. D. Wen, H. T. Cui. "Three-dimensional progressive damage analysis of single fastener joints in composite laminates", Acta Materiae Compositae Sinica, 2005, 22(3), pp. 168-174. 